\title{
Asymmetric Investor Sentiment and Broker Sentiment Contagionin the U.S. Equity Market
}

\author{
Huijian Dong ${ }^{1}$ \\ ${ }^{1}$ College of Business, Pacific University, Oregon, USA \\ Correspondence: Huijian Dong, College of Business, Pacific University, 2043 College Way, Gorest Grove, OR \\ 97116, USA. Tel: 1-503-352-1462. E-mail: hdong@pacificu.edu
}

Received: August 18, 2014

Accepted: August 25, 2014

Online Published: October 25, 2014

doi:10.5539/ijef.v6n11p160

URL: http://dx.doi.org/10.5539/ijef.v6n11p160

\begin{abstract}
This paper uses two types of daily and monthly investor sentiment measures and an indicator of broker sentiment to identify the dynamic linkages of the investor and broker sentiments. I categorize market sentiment into extreme, modest, and representative levels. Then I use unrestricted VAR and Granger causality tests to reveal the sentiments spillover between the counterparties of equity transaction at positive and negative return environments. The main findings are: previous investor sentiments affect the current investor and broker sentiments in the same direction, yet previous broker sentiments do not significantly affect the current investor sentiment. Standard\& Poor's 100, 500, and NASDAQ-based investor sentimentsshow frequent self-corrections, while the DOW-based sentiment is persistent. Furthermore, extremely negative investor sentimentasy mmetrically dominates the equity market.In addition, brokers only take the consensus of investor sentiments as reference for the bullish stocks; while for the bearish stocks, broker sentiment is mostly affected by the extreme investor gauges and less by consensus. Pessimistic broker sentiment is not the cause but the effect of investor fear.
\end{abstract}

Keywords: investor sentiment, market sentiment, broker, bid-ask spread, contagion, equity market

\section{Introduction}

This paper attempts to identify the contagion routines between various types of investor sentiment and broker sentiment in bullish and bearish equity markets of the United States. This is the first study that distinguishes the sentiments between the two counterparties of equity transaction: investors and brokers. I use the Vector autoregression (VAR) models and causality tests to explore the relationships of extreme, modest, and consensus investor opinions and broker gauge of the market. All these tests are separated by the stocks with positive and negative returns to examine the asymmetric market sentiment contagion.

Previous studies do not specify the broker sentiment, and the notions of market sentiment and investor sentiment are interchangeable (Alimov \& Mikkelson, 2012; Chen, Chen, \& Lee, 2013; Berger \& Turtle, 2012). Therefore the existing literature do not focus on the contagion of different sentiments in one market. Instead, the previous researches emphasize mainly the interaction of sentiment and the security returns (Brown \& Cliff, 2004; Joseph, Wintoki, \& Zhang, 2011; Laborda \& Olmo, 2013), or the sentiment contagion among geographically different markets (Baker, Wurgler, \& Yuan, 2012). The conclusions of previous findings are contingent to the choice of sentiment proxy (Corredor, Ferrer, \& Santamaria, 2013). Hence I first attempt to categorize and compare the measures of sentiment in the past studies.

One of the most widely used sentiment measure is the Baker and Wurgler (BW thereafter) market sentiment index $(2006,2007)$. The representative literature thatutilizes the BW index as the barometer of market is Stambaugh, Yu and Yuan (2012). Another popular indicator of market sentiment is the Volatility Index (VIX) (Ben-Rephael, Kandel, \& Wohl, 2012).

A different stream of researches employs the Index of Consumer Sentimentproduced by the University of Michigan Survey Research Center as market sentiment indicator. Studies frequently cite this series. For example, Akhtar, Faff, Oliver and Subrahmanyam (2012) is the representative study of such category. This method is different from my study and is not adopted. One of the main reasons is that the consumer sentiment index is survey-based instead of market based. In other words, the BW index and the VIX index are objectively observed 
from market prices yet the consumer sentiment is compiled from the feelings of heterogeneous agents. Another main reason is that consumer sentiment is a rather broad measure in goods and services market vis-à-vis the security market. In addition, the consumer sentiment variable contains only one series of monthly data and does not separately provide the consumer extreme or modest gauge of future financial market performance.

This study uses the BW index and theVIX indices as the proxy of market sentiment of the investor side. Investors move towards panic when the BW value and VIX value increases. On the other hand, the change of bid-ask spread per dollar equity price represents indicate the sentiment of the broker side.

For the broker sentiment measure, an ideal start point is the signal of bid-ask spread sent by brokers. the bid-ask spread per dollar equity price is the value of broker bid-ask spread divided by the price of the common stock. The measure of bid-ask spread per dollar equity price excludes the factors related to the size of the stock. In addition, the change of bid-ask spread per dollar equity price differentiates the processing cost of brokers and represents the willingness of brokers to take inventory risk and adverse information risk. When the magnitude of such change of level increases, the broker sentiment becomes negative.

The daily VIX indices in my study include four series: option volatilities based on Stand and Poor's (S\&P) 100 and 500 indices, the Dow Jones Industrial Average, and the National Association of Securities Dealers Automated Quotations (NASDAQ). For each of the daily index, I calculate its monthly maximum, minimum, median, and representative levels as the investor extreme fear, optimistic, modest, and consensus sentiments. Then I calculate the monthly returns of stocks and categorize three return groups: total, positive, and negative returns. These groups assist the aim to explore the possible asymmetric pattern in sentiment contagion.

I adopt the unrestricted VAR in this paper as suggested by Gospodinov, Herrera and Pesavento (2013), rather than the regular multi-variable linear regression or vector error correction model (VECM), as some variables are not covariance stationary.The followed Granger causality tests aims to provide a clear clue of sentiments linkages. The results of the VAR based on the BWmarket sentiment are not consistent with the conclusions using VIX as the market sentiment indicator.

The VAR regression with market consensus sentiment and broker sentiment shows thatwhen the previous month market sentiment is bullish, the current market fear will decline and the bid-ask spread will shrink. Such pattern is completely consistent within all the positive and negative return types, and is highly consistent with the S\&P 100, 500, and Dow-based VIX. However, previous broker sentiments with one lag will affect the current broker sentiment inversely in terms of S\&P 100, 500, and NASDAQ. Such inverse relationship disappeared in the Dow-based VIX. The earlier investor sentiments with two lags affect the current broker sentiment in the opposite way, compared to the later investor sentiments with one lag. Such phenomenon is significantly consistent in those three indices, yet different in terms of the VIX formed with Dow Jones Industrial Average.

The VAR regression with market extreme negative sentiment and broker sentiment indicates similar contagion routine with the above consensus regression. Previous market panics with one lag will continue affect the current market panics and broker panics. Oppositely, broker panicsin the previous one and two months will reduce the current broker panics, buthistorical broker panics do not affect the current market panics. In contrast, the relationship between extreme positive investor sentiment and broker sentiment is quite different. For optimistic investor sentiment, market return has a significant role: with the stocks that have positive returns, investor sentiments do not affect broker sentiments, and vice versa. Nevertheless, with the negative stock returns, current investor optimism is affected by its own historical levels, while current broker optimism is affected by both of the historical broker and investor optimism.

The VAR regression with market modest sentiment and broker sentiment strengthens the robustness of the conclusion that the panic atmosphere dominates the market. Different return patterns continue to play lesser role in the VAR regressions. Previous investor sentiments positively affect the current investor and broker sentiments, while previous broker sentiments negatively affect current broker sentiments, and are not influential to the current investor sentiments.

The Granger causality tests based on the bid-ask spread of stocks with all the returns reveal that when theBWindex is used as the proxy of investor sentiment, the broker and investor sentiments do not Granger cause each other. Nevertheless, when the VIX index is used as the proxy of investor sentiment, it Granger causes broker sentiments. In contrast, broker sentiment can only Granger cause the median level of investor sentiment, while cannot affect the extreme panic or overoptimism among the investors.

The Granger causality tests are based on transactions with only positive returns, the influence of sentiments are weaker. Only the median of the investor sentiments can persistently Granger cause broker sentiments, while 
broker sentiments have almost no role in affecting the investor enthusiasm. However, when the causality tests involve only negative returns, investor sentiments can always Granger cause broker sentiments, but the opposite does not hold in panic atmosphere. In other words, when the realized returns of stocks are negative, broker sentiment is affected by investor panics; while the panic of investors is not generated by brokers, but by the herding behaviors of themselves.

\section{Data and Methodology}

This study uses panel regressions with time series data from equity and derivatives markets. The description of the raw data in this paper is presented in Table 1 BWindex, and the VIX indices, can serve as proxy of market sentiment from the investor side. On the other hand, the change of bid-ask spread per dollar equity price can indicate the sentiment from the broker side.

The BWindex is the market sentiment index suggested in Baker and Wurgler $(2006,2007)$. It is based on first principal component of six (standardized) sentiment proxies: value-weighted dividend premium, IPO volume, first day returns on IPO, closed-end fund discount, equity share in new issues, and NYSE turnover. Each of the proxies has first been orthogonalized with respect to a set of macroeconomic conditions.

The VIX indices are another measure of market sentiment from the investor side. The Chicago Board Options Exchange (CBOE) calculates the CBOE Volatility Index, or VIX. It becomes the benchmark for stock market volatility. VIX measures volatility by using a weighted average of options with a constant maturity of 30 days to expiration. It is based on market portfolio index option prices and incorporates information from the volatility skewness by setting a wide range of exercise prices. VIX is often referred to as the "investor fear gauge", as volatility signifies financial turbulence. During financial stress with steep market declines, VIX tends to rise; while as investor fear subsides, VIX decreases.

The bid-ask spread per dollar equity price is the value of broker bid-ask spread divided by the price of the common stock. Previous studies (Atkins \& Dyl, 1997; Glosten \& Harris, 1988; Menyah \& Paudyal, 2000) conclude that tradingvolume and market value will affect bid-ask spread. The measure of bid-ask spread per dollar equity price will exclude these factors related to the size of the stock. In addition, the change of the level of bid-ask spread per dollar equity price differentiates the processing cost of brokers, which is a fixed cost, and represents the willingness of brokers to take inventory risk and adverse information risk. Such change of level can serve as the indicator of broker sentiment and reaction to the market environment. During financial stress, the change of the level of bid-ask spread per dollar equity price tends to rise; while as investor fear declines, this value decreases.

Table 1. Data facts

\begin{tabular}{|c|c|c|c|c|c|c|c|}
\hline Series & Sample Start & Sample End & Frequency & $\begin{array}{l}\text { Number of } \\
\text { Observation }\end{array}$ & Mean & Median & $\begin{array}{l}\text { Standard } \\
\text { Deviation } \\
\end{array}$ \\
\hline BWIndex & July 1965 & December 2010 & Monthly & 546 & $1.771 \times 10^{-9}$ & -0.014 & 0.999 \\
\hline Bid-ask Spread/ Price & September 1965 & January 2011 & Monthly & 546 & 0.102 & 0.106 & 0.049 \\
\hline VIX NASDAQ & September 22, 2003 & April 25, 2013 & Daily & 2415 & 23.538 & 21.270 & 9.086 \\
\hline VIX Stand and Poor's 100 & January 2, 1986 & April 25, 2013 & Daily & 6886 & 21.454 & 19.770 & 9.132 \\
\hline VIX Stand and Poor's 500 & January 2, 1992 & April 25, 2013 & Daily & 5371 & 20.412 & 18.750 & 8.387 \\
\hline VIX Dow Jones & October 7,1997 & April 25, 2014 & Daily & 3913 & 21.014 & 19.920 & 8.250 \\
\hline
\end{tabular}

Note. BWindex is obtained from Wurgler's website: http://people.stern.nyu.edu/jwurgler/. Bid-ask spreads and common share prices are from Center for Research in Security Prices (CRSP), with Standard Industrial Classification (SIC) code ranging from 0100 to 9999 , and include all NYSE, NASDAQ, and American Stock Exchange (AMEX) listed stocks.. VIX indices based on the Standard \& Poor's 100 and 500 index, NASDAQ, and Dow Jones Industrial Average index are obtained from Chicago Board Options Exchange (CBOE).

I first convert the daily VIX indices into monthly variables. The daily index is the average of daily high and low. There are four daily VIX indices: volatilities based on Stand and Poor's 100 and 500 index, the Dow Jones industrial average, and the NASDAQ. For each of the daily index, I calculate its monthly maximum, minimum, median, and representative levels. The representative level is the arithmetic mean of the maximum, minimum, and the median. Monthly VIX maximum is the highest point of market panic and pessimism, while the monthly VIX minimum is the level of extremely optimistic market sentiment. The monthly median VIX is the general investor attitude excluding outliers. The monthly representative level gives a larger weight to the extreme market emotions and is thus a better measure than the monthly mean of daily VIX index. 
Then I calculate the monthly returns of stocks and categorize three return groups: total, positive, and negative returns. The purpose of such categorization is to test the relationships in Figure 1. The positive and negative returns can generate optimistic or pessimistic sentiments of the investors and brokers, and the two-polar sentiment can in turn create positive or negative returns. The interaction of returns and sentiments is not necessarily consistent, for example, positive returns might lead to positive or negative sentiments. The former is normal reaction and the latter is due to the worry of equity overprice and the unsustainable growth. Figure 1 illustrates the intuitively correct interactions.

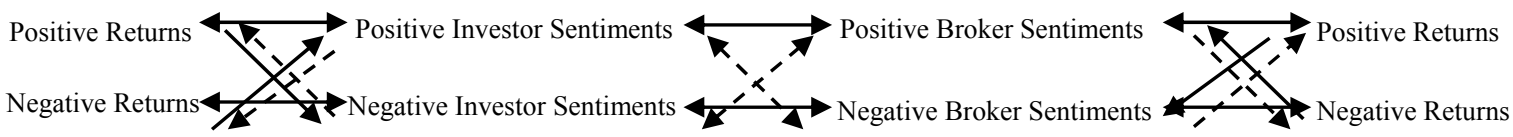

Figure 1. Interaction of returns, investor sentiments, and broker sentiments

Note. The solid arrows represent intuitively correct causal relationships, caused by either normal reaction of counter-reaction of over- or under-price. The dashed arrows represent relationships that are not supported by financial theories.

To determine the empirical model specification, I first run the standard Augmented Dickey-Fuller test (ADF) unit root tests on all the time series variables. All variables are covariance stationary except the BWindex, bid-ask spread per dollar price, and the monthly minimum level of VIX index based on NASDAQ, which have significant unit roots at 5\% significance level. However, the first order differences of these three variables are covariance stationary and can be involved in ordinary least square estimations without violating the basic assumptions of linear regressions. The test involves constant term without the time trend, as there is no definitive pattern of sentiment observed at the first place. The unit root test outputs are reported in Table 2.

Table 2. Unit root test results of all variables

\begin{tabular}{llllllllllll}
\hline Variable & t-Statistic & P Value & Variable & t-Statistic & P Value & Variable & t-Statistic & P Value & Variable & t-Statistic & P Value \\
\hline BW & -2.311 & 0.169 & SPOSS & -2.543 & 0.106 & V100MD & -4.239 & 0.001 & VNASMX & -3.531 & 0.009 \\
HML & -19.923 & 0.000 & RF & -2.172 & 0.217 & V100MI & -4.213 & 0.001 & VNASMD & -3.022 & 0.036 \\
MKTRP & -21.376 & 0.000 & SMB & -22.050 & 0.000 & V500AV & -3.690 & 0.005 & VNASMI & -2.556 & 0.105 \\
MOM & -21.894 & 0.000 & TOTR & -17.064 & 0.000 & V500MX & -4.355 & 0.000 & VDOWAV & -4.327 & 0.001 \\
NEGR & -3.308 & 0.015 & STOTS & -2.554 & 0.103 & V500MD & -3.674 & 0.005 & VDOWMX & -3.951 & 0.002 \\
SNEGS & -2.795 & 0.060 & V100AV & -5.121 & 0.000 & V500MI & -3.181 & 0.022 & VDOWMD & -4.311 & 0.001 \\
POSR & -2.798 & 0.059 & V100MX & -6.416 & 0.000 & VNASAV & -3.292 & 0.018 & VDOWMI & -3.240 & 0.019 \\
\hline
\end{tabular}

Note. BW is the BW index; HML is the high-minus-low risk premium; MKTRP is the market portfolio risk premium; MOM is the momentum risk premium; NEGR is the negative returns; SNEGS is the standardized negative return spread per unit of price; POSR is the positive returns; SPOSP is the standardized positive return spread per unit of price; RF is the risk free interest rate; SMB is the small-minus-large risk premium; TOTR is the total returns; STOTS is the standardized total return spread per unit of price; V100AV is the average level of the S\&P 100-based VIX index; V100MX is the maximum level of the S\&P 100-based VIX index; V100MD is the median level of the S\&P 100-based VIX index; V100MI is the minimum level of the S\&P 100-based VIX index; same rules apply to the S\&P 500-based, NASDAQ-based, and DOW-based variables. The null hypothesis of the unit root test is unit roots present, and P values lower than 0.05 rejects such hypothesis, i.e., confirms that the variable is covariance stationary.

As the above-mentioned variables in panel regressions are with unit roots but some are covariance stationary, a restricted VAR model with embedded cointegrated relations is not appropriate for the purpose of describing the linkages of the investor sentiments and broker sentiments. To better test the endogenous memory effect of sentiments, I adopt the unrestricted VAR in this paper, rather than the regular multi-variable linear regression. The variable names in the VAR regressions are introduced in Table 3. 
Table 3. Notation of variables

\begin{tabular}{ll}
\hline Variable Prefix and Suffix & Notation \\
\hline $\mathrm{d}$ & First order difference \\
bw & BWindex \\
& General notation of first order difference of bid-ask spread divided by stock price, t, p, \\
dspread_ & and $n$ is with total, positive, and negative returns, respectively. \\
& VIX index based on the Standard and Poor's 100 index \\
v5 & VIX index based on the Standard and Poor's 500 index \\
vn & VIX index based on the NASDAQ index \\
vd & VIX index based on the NASDAQ index \\
max & Monthly maximum of the daily VIX index \\
min & Monthly minimum of the daily VIX index \\
median & Monthly minimum of the daily VIX index \\
rep & Average of the max, min, and median of the daily VIX index \\
\hline
\end{tabular}

Note. Variables are assembled with the prefixes and suffixes. For example, dvnmin is the first order difference of the monthly minimum of the VIX index based on NASDAQ.

I first test the proper lags included in the VAR model and the results show that two is the optimal amount of lags. The general VAR model tested is:

$$
\begin{aligned}
& \text { Market Sentiment }_{t}=\phi_{1,11} \text { Market Sentiment } t_{t-1}+\phi_{1,21} \text { Broker Sentiment }_{t-1}+\phi_{2,11} \text { Marekt Sentiment }_{t-2} \\
&+\phi_{2,21} \text { Broker Sentiment }_{t-2}+c_{1}+\varepsilon_{1, t} \\
& \text { Broker Sentiment }_{t}=\phi_{1,12} \text { Broker Sentiment }_{t-1}+\phi_{1,22} \text { Market Sentiment }_{t-1}+\phi_{2,12} \text { Broker Sentiment }_{t-2} \\
&+\phi_{2,22} \text { Market Sentiment }{ }_{t-2}+c_{2}+\varepsilon_{2, t}
\end{aligned}
$$

The theoretical implications of significant VAR coefficients are stated as follows. The coefficient matrix $\Phi_{i=1,1}$ represents the direct effects of previous market (broker) sentiment to the current market (broker) sentiment; while the coefficient matrix $\Phi_{i=1,2_{-}}$indicates the cross effects of previous market (broker) sentiment to the current broker (market) sentiment. If $\phi_{i=1,11}>1$ and $\phi_{i=1,21}>1$, the current market sentiment will memorize the previous market and broker sentiment, and amplify such sentiment. This leads to overoptimism or panic. If $0<\phi_{i=1,11}<1$ and $0<\phi_{i=1,21}<1$, the current market (broker) sentiment will memorize the previous market (broker) sentiment, but such memory will fade and lead to a neutral market attitude. On the other hand, if $-1<\phi_{i=1,11}<0$ and $-1<\phi_{i=1,21}<0$, the current sentiment will correct the previous sentiment, yet such correction only partially reverse the earlier overoptimistic or panic atmosphere and gradually bring the sentiment back to steady state. Finally, if $\phi_{i=1,11}<-1$ and $\phi_{i=1,21}<-1$, the current sentiment will reserve the previous market (broker) sentiment but to a greater magnitude. In other words, the sentiments tend to be more volatile in the last case.

The coefficient matrix $\Phi_{i=2}$ represents the lasting direct and cross effects of previous sentiment to the current sentiment. If there is a sign change from $\Phi_{i=2}$ to $\Phi_{i=1}$, the previous sentiment is reversed; while without a sign change, the sentiment is continued.

The magnitudes, signs, and significance levels of the VAR coefficients are reported in Table 4 to 8 . Then I perform further Granger causality tests between the investor sentiments and broker sentiments. The tests are subcategorized by the different returns realized: total, positive, and negative. The detailed regression coefficients are available on request. The main findings are presented in Table 9.

\section{Results and Discussions}

I first run the VAR model using the BW Index as the proxy of market sentiment, and using the change of bid-ask spread per dollar equity price as the proxy of broker sentiment. The regression is performed in three settings: VAR with all returns involved, with only positive returns involved, and with only negative returns involved. Table 3.1 shows the results.

With all the types of returns included in the VAR, previous broker (market) sentiments have no impact on the current market (broker) sentiments. The sentiments from the buyer and seller side of the equity market are not mutually contagious. However, the broker sentiments indicate a unique feature: in each month, the brokers reverse their previous sentiments to the opposite side. On the other hand, the current market sentiment neither memorizes nor reverses the previous market sentiment. These conclusions, based on the BW investor sentiment, 
are not consistent with the following conclusions using VIX as the market sentiment indicator.

Table 4. VAR regression of baker wurgler index and bid-ask spread

\begin{tabular}{llllllllllllll}
\hline & \multicolumn{2}{c}{ dbw } & \multicolumn{2}{c}{ dspreadt } & \multicolumn{2}{c}{ dbw } & \multicolumn{2}{c}{ dspreadp } & \multicolumn{2}{c}{ dbw } & \multicolumn{2}{c}{ dspreadn } \\
\hline Lag1.dbw & 0.081 & 1.880 & 0.005 & 1.490 & 0.098 & $2.250^{* *}$ & 0.003 & 0.700 & 0.077 & 1.780 & 0.001 & 0.180 \\
Lag2.dbw & 0.037 & 0.850 & -0.004 & -1.010 & 0.034 & 0.790 & -0.007 & -1.490 & 0.039 & 0.900 & -0.002 & -0.390 \\
Lag1.dspread__ & 0.040 & 0.080 & -0.225 & $-5.240^{* *}$ & 0.317 & 0.850 & -0.656 & $-15.720^{* *}$ & -0.341 & -0.970 & -0.359 & $-8.450^{* *}$ \\
Lag2.dspread_ & -0.783 & -1.470 & -0.098 & $-2.290^{* *}$ & -0.647 & -1.740 & -0.277 & $-6.630^{* *}$ & 0.121 & 0.340 & -0.174 & $-4.060^{* *}$ \\
Constant & 0.003 & 0.380 & 0.000 & 0.080 & 0.004 & 0.580 & 0.000 & 0.040 & 0.004 & 0.530 & 0.000 & 0.120 \\
\hline
\end{tabular}

Note. dbw is the first order difference of BW(2006, 2007) Index. dspread_is the first order difference of the bid-ask spread per dollar equity price. The first two columns are VAR with all returns involved; the second two columns are VAR with only positive returns involved; and the last two columns are with only negative returns involved. * is significant at $5 \%$ and $* *$ is significant at $1 \%$.

Then I switch to use VIX as the market sentiment indicator. Table 5 uses all the monthly representatives of the VIX series, which are the average of the monthly maximum, minimum, and median. The results indicated that: firstly, previous investor sentiments with one lag will affect the current investor sentiments and broker sentiments in the same direction. When the previous month market sentiment is bullish, the current market fear will decline and the bid-ask spread will shrink. Such pattern is completely consistent within all the positive and negative return types, and is highly consistent with the S\&P 100, 500, and Dow-based VIX. There is trivial exception in the results of the NASDAQ-based VIX, which as the smallest observation sample set in my study.

Secondly, previous broker sentiments with one lag will affect the current broker sentiment, yet not affecting the current market sentiment at all. In Table 5, all the VAR coefficients between Lag1.dspread_and v1rep, v5rep, vnrep, and vdrep are insignificant, with one exception. All the coefficients between Lag1.dspread_and dspreadt, dspreadp, and dspreadn are significantly negative, indicating that previous broker sentiments with one lag will affect the current broker sentiment inversely. Brokers' sentiments tend to be bullish when the previous broker sentiments are bearish in terms of S\&P 100, 500, and NASDAQ. Such inversed relationship disappeared in the Dow-based VIX. The last row of Table 5 indicates that, historical broker sentiments generate same present broker sentiments. The results are consistent in the three return types.

Thirdly, in terms of the VIX series based on the Stand and Poor's 100 and 500 indices, and the NASDAQ index, the earlier investor sentiments with two lags affect the current broker sentiment in the opposite way, compared to the later investor sentiments with one lag. Such phenomenon is significantly consistent in those three indices, yet different in terms of the VIX formed with Dow Jones Industrial Average. The previous one-lag and two-lag market sentiment indicated by the Dow-based VIX affect the current broker sentiment in the same way. Both previous levels of market sentiment strengthen the current broker sentiment. The S\&P-based and the NASDAQ-based VIX contain more sentiment corrections, while the DOW-based market sentiment is more persistent over time.

Frequent sentiment corrections can be interpreted as more unstable market views and less investor rationality, or more efficient investor self-correction and quicker equilibrium convergence. Therefore, this paper cannot draw the conclusion about the sentiment-indicated market rationality or efficiency. In addition, no theoretical basis exists to address the issue that the same group of investors have stable sentiment with Dow, while unstable sentiment with S\&P and NASDAQ. However, the results in Table 5 can be employed to predict the investor sentiments: if the present investor sentiments are bearish, the future market and broker sentiments would be bullish in terms of S\&P 100, 500, and NASDAQ; while the future market and broker sentiments would be bearish in terms of Dow, if the current investor sentiments are bearish. 
Table 5. VAR regression of VIX index monthly representative and Bid-ask spread

\begin{tabular}{|c|c|c|c|c|c|c|c|c|c|c|c|c|}
\hline \multirow[b]{2}{*}{ Lag1.v1rep } & \multicolumn{2}{|l|}{ v1rep } & \multicolumn{2}{|c|}{ dspreadt } & \multicolumn{2}{|l|}{ v1rep } & \multicolumn{2}{|c|}{ dspreadp } & \multicolumn{2}{|l|}{ v1rep } & \multicolumn{2}{|c|}{ dspreadn } \\
\hline & 0.873 & $13.630 * *$ & 0.001 & $3.310 * *$ & 0.881 & $14.520 * *$ & 0.001 & $3.410 * *$ & 0.892 & $15.050 * *$ & 0.001 & $4.490 * *$ \\
\hline Lag2.v1rep & -0.022 & -0.360 & -0.001 & $-3.800 * *$ & -0.036 & -0.600 & -0.001 & $-3.310 * *$ & -0.043 & -0.730 & -0.001 & $-4.400 * *$ \\
\hline Lag1.dspread_ & 16.254 & 0.800 & -0.357 & $-5.730 * *$ & 6.615 & 0.510 & -0.744 & $-13.070 * *$ & -2.852 & -0.220 & -0.473 & $-8.420 * *$ \\
\hline Lag2.dspread_ & -25.606 & -1.360 & -0.152 & $-2.620 * *$ & -4.368 & -0.340 & -0.330 & $-5.920 * *$ & -14.250 & -1.090 & -0.222 & $-3.990 * *$ \\
\hline \multirow[t]{2}{*}{ Constant } & 3.249 & $4.290 * *$ & 0.001 & 0.520 & 3.382 & $4.500 * *$ & -0.001 & -0.400 & 3.289 & $4.370 * *$ & -0.002 & -0.460 \\
\hline & \multicolumn{2}{|l|}{ v5rep } & \multicolumn{2}{|c|}{ dspreadt } & \multicolumn{2}{|l|}{ v5rep } & \multicolumn{2}{|c|}{ dspreadp } & \multicolumn{2}{|l|}{ v5rep } & \multicolumn{2}{|c|}{ dspreadn } \\
\hline Lag1.v5rep & 1.093 & $15.810 * *$ & 0.001 & $3.290 * *$ & 1.078 & $16.190 * *$ & 0.001 & $2.320 * *$ & 1.096 & $16.690 * *$ & 0.001 & $3.640 * *$ \\
\hline Lag2.v5rep & -0.209 & $-3.070 * *$ & -0.001 & $-3.440 * *$ & -0.201 & $-3.050 * *$ & -0.001 & $-2.090 * *$ & -0.214 & $-3.290 * *$ & -0.001 & $-3.570 * *$ \\
\hline Lag1.dspread_ & 10.744 & 0.650 & -0.435 & $-6.430 * *$ & 10.143 & 0.970 & -0.758 & $-11.890 * *$ & -3.143 & -0.290 & -0.533 & $-8.500 * *$ \\
\hline Lag2.dspread_ & -29.841 & -1.860 & -0.238 & $-3.620 * *$ & 0.245 & 0.020 & -0.343 & $-5.380 * *$ & -16.524 & -1.550 & -0.276 & $-4.420 * *$ \\
\hline \multirow[t]{2}{*}{ Constant } & 2.386 & $3.660 * *$ & 0.000 & -0.150 & 2.561 & $3.930 * *$ & -0.003 & -0.810 & 2.439 & $3.740 * *$ & -0.002 & -0.490 \\
\hline & \multicolumn{2}{|l|}{ vnrep } & \multicolumn{2}{|c|}{ dspreadt } & \multicolumn{2}{|l|}{ vnrep } & \multicolumn{2}{|c|}{ dspreadp } & \multicolumn{2}{|l|}{ vnrep } & \multicolumn{2}{|c|}{ dspreadn } \\
\hline Lag1.vnrep & 1.124 & $9.860 * *$ & 0.001 & $3.580 * *$ & 1.059 & $9.950 * *$ & 0.001 & 1.920 & 1.097 & $10.370 * *$ & 0.002 & $3.470 * *$ \\
\hline Lag2.vnrep & -0.237 & $-2.190 * *$ & -0.001 & $-3.100 * *$ & -0.205 & -1.960 & -0.001 & -1.050 & -0.221 & $-2.130 * *$ & -0.001 & $-2.780 * *$ \\
\hline Lag1.dspread_ & -17.774 & -0.470 & -0.671 & $-6.060 * *$ & 11.321 & 0.570 & -0.855 & $-8.670 * *$ & -23.065 & -0.960 & -0.823 & $-8.260 * *$ \\
\hline Lag2.dspread_ & -86.766 & $-2.340 * *$ & -0.308 & $-2.850 * *$ & -1.096 & -0.050 & -0.424 & $-4.280 * *$ & -45.502 & -1.890 & -0.352 & $-3.540 * *$ \\
\hline \multirow[t]{2}{*}{ Constant } & 2.657 & 1.950 & -0.005 & -1.340 & 3.515 & $2.580 * *$ & -0.012 & -1.720 & 2.957 & $2.190 * *$ & -0.008 & -1.440 \\
\hline & \multicolumn{2}{|l|}{ vdrep } & \multicolumn{2}{|c|}{ dspreadt } & \multicolumn{2}{|l|}{ vdrep } & \multicolumn{2}{|c|}{ dspreadp } & \multicolumn{2}{|l|}{ vdrep } & \multicolumn{2}{|c|}{ dspreadn } \\
\hline Lag1.vdrep & 0.084 & $13.300 * *$ & 0.000 & $3.280 * *$ & 0.079 & $14.110^{* *}$ & 0.001 & $2.770 * *$ & 0.079 & $14.200 * *$ & 0.000 & $3.470 * *$ \\
\hline Lag2.vdrep & 0.082 & $-3.060 * *$ & 0.000 & $-3.580 * *$ & 0.078 & $-3.260 * *$ & 0.001 & $-2.530 * *$ & 0.0779 & $-3.330 * *$ & 0.000 & $-3.530 * *$ \\
\hline Lag1.dspread_ & 20.257 & 0.770 & 0.081 & $-4.650 * *$ & 12.145 & 0.600 & 0.074 & $-9.900 * *$ & 13.524 & 0.000 & 0.077 & $-7.170 * *$ \\
\hline Lag2.dspread_ & 19.584 & -1.630 & 0.078 & $-2.860 * *$ & 12.145 & -0.510 & 0.074 & $-5.240 * *$ & 13.419 & -1.010 & 0.076 & $-2.930 * *$ \\
\hline Constant & 0.850 & $3.370 * *$ & 0.003 & 0.300 & 0.851 & $3.580 * *$ & 0.005 & -0.650 & 0.853 & $3.490 * *$ & 0.005 & -0.130 \\
\hline
\end{tabular}

Note. v1/5/n/drepare monthly representative levels of the S\&P 100, 500, NASDAQ, and Dow Jones index option based VIX Index. dspread is the first order difference of the bid-ask spread per dollar equity price. The first two columns are VAR with all returns involved; the second two columns are VAR with only positive returns involved; and the last two are with only negative returns. $*$ is significant at $5 \%$ and $* *$ is significant at $1 \%$

The following Table 6, 7 and 8 serve as comparisons and robustness tests to Table 5. The market sentiment measure in Table 6 is the monthly maximum value of the daily VIX series, and the market sentiment indicator in Table 7 is the minimum value. These two variables represent the extreme attitudes of the market. The VAR regressions in Table 6 and 7 aim to reveal the role of panic and high level optimism in the equity market. On the opposite side, Table 8 uses the monthly median of VIX as proxy of investor sentiments to exclude the extreme emotion outliers.

The results in Table 6 are highly similar with Table 5. The maximum level of VIX indices is the highest market fear, as VIX is the volatility of index options. Greater volatility at all option strike price levels implies more equity price change uncertainty and less investor agreements. The VAR output exhibited in Table 6 indicates that:

Previous market panics with one lag will continue affect the current market panics and broker panics. Oppositely, broker panicsin the previous one and two months will reduce the current broker panics, buthistorical broker panics do not affect the current market panics. In addition, for the S\&P and NASDAQ-based VIX, the earlier investor sentiments with two lags affect the current broker sentiment in the opposite way, compared to the later investor sentiments with one lag; nevertheless, for the Dow-based VIX, the previous one-lag and two-lag market panics affect the current broker panics in the same way. All these conclusions are completely consistent within all the positive and negative return types.

The similarity of Table 6 and 5 not only serves as the robustness check of the earlier conclusion addressed, but more importantly reveals the fact that panic market sentiment dominates in the equity market. The impact of panic is persistent in the market sentiment and can affect brokers' willingness of transaction and market making. In contrast, broker panic has no role in affecting market sentiment. The extreme atmosphere in the equity market 
in the United States is asymmetric. The effects of overoptimism are less influential, as reported in Table 7.

Table 6. VAR regression of VIX index monthly maximum and Bid-ask spread

\begin{tabular}{|c|c|c|c|c|c|c|c|c|c|c|c|c|}
\hline \multirow[b]{2}{*}{ Lag1.v1max } & \multicolumn{2}{|c|}{ v1max } & \multicolumn{2}{|c|}{ dspreadt } & \multicolumn{2}{|c|}{ v1max } & \multicolumn{2}{|c|}{ dspreadp } & \multicolumn{2}{|c|}{ v1max } & \multicolumn{2}{|c|}{ dspreadn } \\
\hline & 0.518 & $8.390^{* *}$ & 0.000 & $2.010^{* *}$ & 0.535 & $9.030^{* *}$ & 0.000 & $2.980^{* *}$ & 0.537 & $9.220^{* *}$ & 0.000 & $3.000^{* *}$ \\
\hline Lag & 0.189 & $3.150^{* *}$ & -0.000 & $-2.540^{* *}$ & 0.169 & $2.900^{* *}$ & 0.000 & $-2.540^{* *}$ & .170 & $2.950^{* *}$ & 0.000 & $-2.300^{* *}$ \\
\hline Lag1.dspread_ & 35.645 & 0.850 & -0.313 & $-5.080^{* *}$ & 3.924 & 0.140 & -0.730 & $-12.880^{* *}$ & 2.516 & 0.090 & -0.452 & $-7.900^{* *}$ \\
\hline Lag2.dspread_ & -33.207 & -0.830 & -0.120 & $-2.030^{* *}$ & -9.623 & -0.360 & -0.310 & $-5.560^{* *}$ & -19.331 & -0.690 & -0.212 & $-3.720^{* *}$ \\
\hline \multirow[t]{2}{*}{ Constant } & 7.463 & $5.290^{* *}$ & 0.001 & 0.300 & 7.539 & $5.440^{* *}$ & -0.002 & -0.690 & 7.469 & $5.370^{* *}$ & -0.003 & -1.010 \\
\hline & \multicolumn{2}{|c|}{ v5max } & \multicolumn{2}{|c|}{ dspreadt } & \multicolumn{2}{|c|}{ v5max } & \multicolumn{2}{|c|}{ dspreadp } & \multicolumn{2}{|c|}{ v5max } & \multicolumn{2}{|c|}{ dspreadn } \\
\hline Lag1.v5max & 0.972 & $13.830^{* *}$ & 0.001 & $2.680^{* *}$ & 0.962 & $14.280^{* *}$ & 0.001 & $2.470^{* *}$ & 0.979 & $14.620^{* *}$ & 0.001 & $2.480^{* *}$ \\
\hline Lag2.v5max & -0.115 & -1.670 & -0.001 & $-2.820^{* *}$ & -0.114 & -1.700 & -0.001 & $-2.140^{* *}$ & -0.124 & -1.870 & -0.001 & $-2.330^{* *}$ \\
\hline Lag1.dspread_ & 10.784 & 0.450 & -0.423 & $-6.180^{* *}$ & 11.718 & 0.780 & -0.758 & $-11.930^{* *}$ & -4.047 & -0.260 & -0.526 & $-8.210^{* *}$ \\
\hline Lag2.dspread_ & -37.762 & -1.640 & -0.221 & $-3.360^{* *}$ & 1.717 & 0.110 & -0.340 & $-5.370^{* *}$ & -24.661 & -1.610 & -0.270 & $-4.250^{* *}$ \\
\hline \multirow[t]{2}{*}{ Constant } & 3.384 & $3.790^{* *}$ & -0.001 & -0.210 & 3.628 & $4.080^{* *}$ & -0.004 & -0.930 & 3.433 & $3.870^{* *}$ & -0.002 & -0.620 \\
\hline & \multicolumn{2}{|c|}{ vnmax } & \multicolumn{2}{|c|}{ dspreadt } & \multicolumn{2}{|c|}{ vnmax } & \multicolumn{2}{|c|}{ dspreadp } & \multicolumn{2}{|c|}{ vnmax } & \multicolumn{2}{|c|}{ dspreadn } \\
\hline Lag1. & 1.081 & $9.400^{* *}$ & 0.001 & $3.190^{* *}$ & 1.035 & 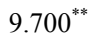 & 0.001 & 1.870 & 1.063 & $9.910^{* *}$ & 0.001 & $2.620^{* *}$ \\
\hline Lag2.vnmax & -0.223 & $-2.040^{* *}$ & -0.001 & $-2.640^{* *}$ & -0.205 & -1.950 & -0.000 & -0.890 & -0.217 & $-2.060^{* *}$ & -0.001 & -1.870 \\
\hline Lag1.dspread_ & -23.616 & -0.460 & -0.651 & $-5.830^{* *}$ & 12.096 & 0.450 & -0.858 & $-8.680^{* *}$ & -26.711 & -0.820 & -0.808 & $-7.910^{* *}$ \\
\hline Lag2.dspread_ & -81.565 & -1.640 & -0.281 & $-2.600^{* *}$ & -1.843 & -0.070 & -0.426 & $-4.290^{* *}$ & -36.619 & -1.130 & -0.334 & $-3.290^{* *}$ \\
\hline \multirow[t]{2}{*}{ Constant } & 3.848 & $2.230^{* *}$ & -0.005 & -1.310 & 4.639 & $2.730^{* *}$ & -0.011 & -1.780 & 4.185 & $2.470^{* *}$ & -0.008 & -1.410 \\
\hline & \multicolumn{2}{|c|}{ vdmax } & \multicolumn{2}{|c|}{ dspreadt } & \multicolumn{2}{|c|}{ vdmax } & \multicolumn{2}{|c|}{ dspreadp } & \multicolumn{2}{|c|}{ vdmax } & \multicolumn{2}{|c|}{ dspreadn } \\
\hline Lag1.vdmax & 0.086 & $11.180^{* *}$ & 0.000 & $3.330^{* *}$ & 0.081 & $11.960^{* *}$ & 0.000 & $3.310^{* *}$ & 0.082 & $11.900^{* *}$ & 0.000 & $2.660^{* *}$ \\
\hline Lag2.vdmax & 0.083 & -1.430 & 0.000 & $-3.620^{* *}$ & 0.080 & -1.710 & 0.000 & $-2.950^{* *}$ & 0.080 & -1.710 & 0.000 & $-2.640^{* *}$ \\
\hline Lag1.dspread_ & 28.337 & 1.060 & 0.080 & $-4.640^{* *}$ & 17.060 & 0.660 & 0.074 & $-10.100^{* *}$ & 19.090 & 0.230 & 0.078 & $-6.890^{* *}$ \\
\hline Lag2.dspread_ & 27.412 & -1.300 & 0.078 & $-2.760^{* *}$ & 17.065 & -0.590 & 0.074 & $-5.380^{* *}$ & 18.904 & -0.600 & 0.077 & $-2.750^{* *}$ \\
\hline Constant & 1.155 & $3.390^{* *}$ & 0.003 & 0.170 & 1.151 & $3.550^{* *}$ & 0.005 & -0.850 & 1.155 & $3.520^{* *}$ & 0.005 & -0.280 \\
\hline
\end{tabular}

Note. v1/5/n/dmaxare monthly maximum levels of the S\&P 100, 500, NASDAQ, and Dow Jones index option based VIX Index. dspread_is the first order difference of the bid-ask spread per dollar equity price. The first two columns are VAR with all returns involved; the second two columns are VAR with only positive returns involved; and the last two are with only negative returns. * is significant at $5 \%$ and $* *$ is significant at $1 \%$

The mutual influence linkages of investor sentiments and broker sentiments are different when the investor sentiments are measured by the lowest fear level of the VIX index, as demonstrated in Table 7. In the above results, market returns do not affect the relations between the investor representative and panic sentiments and broker sentiments. However, market returns are significantly influential to the relations between the investor optimism and broker sentiments. With only the stocks that have positive returns, investor sentiments do not affect broker sentiments, and vice versa. The coefficients in the cross regressions of the second main column of Table 7 are not significant. This column also implies that investor and broker sentiments have memory effects and the optimism of the both sides in equity transaction is persistent. In contrast, with only the negative stock returns, current investor optimism is affected by its own historical levels, while current broker optimism is affected by both of the historical broker and investor optimism. To summarize, the routines of investor and broker sentiment contagion is different when the market atmosphere is different. Panics from the investors will infect brokers, but optimism does not mutually infect the transaction parties.

In order to exclude the extreme sentiment outliers in the market and examine the consensus sentiment of investors, I also perform the VAR regression between the median VIX and the change of bid-ask spread per dollar price. The former is a measure of modest investor attitude and the latter still serves as the measure of broker sentiment. The results are reported in Table 8 . 
Table 7. VAR regression of VIX index monthly minimum and Bid-ask spread

\begin{tabular}{|c|c|c|c|c|c|c|c|c|c|c|c|c|}
\hline \multirow[b]{2}{*}{ Lag1.v1min } & \multicolumn{2}{|c|}{$\mathrm{v} 1 \mathrm{~min}$} & \multicolumn{2}{|c|}{ dspreadt } & \multicolumn{2}{|c|}{ v1min } & \multicolumn{2}{|c|}{ dspreadp } & \multicolumn{2}{|c|}{ v1min } & \multicolumn{2}{|c|}{ dspreadn } \\
\hline & 0.896 & $14.810^{* *}$ & 0.001 & $2.970^{* *}$ & 0.902 & $15.420^{* *}$ & 0.001 & 1.730 & .936 & $15.930^{* *}$ & 0.002 & $4.760^{* *}$ \\
\hline Lag2.v1min & 0.000 & 0.010 & -0.001 & $-3.480^{* *}$ & 0.010 & -0.170 & -0.001 & -1.870 & 0.042 & -0.710 & -0.002 & $-5.000^{* *}$ \\
\hline Lag1.dspread & 46.043 & $4.000^{* *}$ & -0.321 & $-5.440^{* *}$ & 28.386 & $3.720^{* *}$ & -0.705 & $-12.570^{* *}$ & .630 & 1.190 & -0.468 & $-8.450^{* *}$ \\
\hline Lag2.ds & -4.708 & & -0.182 & $3.060^{* *}$ & 14.917 & & -0.318 & & & & -0.241 & $-4.350^{* *}$ \\
\hline \multirow[t]{2}{*}{ Constant } & 948 & ? $0^{* *}$ & 0.002 & 0.870 & 2.015 & $3.980^{* *}$ & .001 & 0.170 & 961 & $3.790^{* *}$ & 0.001 & 0.250 \\
\hline & \multicolumn{2}{|c|}{$\mathrm{v} 5 \mathrm{~min}$} & \multicolumn{2}{|c|}{ dspreadt } & \multicolumn{2}{|c|}{$\mathrm{v} 5 \mathrm{~min}$} & \multicolumn{2}{|c|}{ dspreadp } & \multicolumn{2}{|c|}{$\mathrm{v} 5 \mathrm{~min}$} & \multicolumn{2}{|c|}{ dspreadn } \\
\hline Lag1.v5 & 1.001 & $14.400^{* *}$ & 0.001 & $2.890^{* *}$ & 0.996 & $14.800^{* *}$ & 0.001 & 1.170 & 1.021 & $15.380 * *$ & 0.002 & $4.630^{* *}$ \\
\hline Lag2.v5min & -0.103 & -1.500 & -0.001 & & -0.102 & -1.530 & -0.001 & -1.080 & -0.124 & & -0.002 & \\
\hline Lag1.dspread_ & 19.458 & & -0.419 & $-6.250^{* *}$ & 12.288 & & & & & & & $-8.680^{* *}$ \\
\hline Lag z.usp & -11.321 & 0.910 & -0.233 & & 7.912 & 0.980 & -0.328 & & -8.546 & & -0.277 & \\
\hline \multirow[t]{2}{*}{ Constant } & 1.829 & & 0.000 & 0070 & 1.913 & & -0.002 & -0. & & & -0.001 & -0.270 \\
\hline & \multicolumn{2}{|c|}{ dvnmin } & \multicolumn{2}{|c|}{ dspreadt } & \multicolumn{2}{|c|}{ dvnmin } & \multicolumn{2}{|c|}{ dspreadp } & \multicolumn{2}{|c|}{ dvnmin } & \multicolumn{2}{|c|}{ dspreadn } \\
\hline $\operatorname{in}$ & 0.222 & & 0.001 & & 0.172 & 1.650 & 0.000 & 0.160 & & 1.860 & 0.002 & \\
\hline Lag2.dvnmin & -0.213 & & 0.000 & 0.030 & & $-3.010^{* *}$ & 0.001 & & & & 0.001 & \\
\hline read_ & -15.458 & -0.560 & -0.603 & & -0.815 & & -0.810 & & -11.329 & -0.630 & -0.845 & \\
\hline Lag2.dspread_ & -65.105 & & -0.252 & & & & -0.387 & & -35.746 & & & \\
\hline \multirow[t]{2}{*}{ Constant } & & & 0.000 & -0.050 & -0.108 & & 0.000 & -0.060 & .105 & & 0.000 & 0.080 \\
\hline & \multicolumn{2}{|c|}{ vdmin } & \multicolumn{2}{|c|}{ dspreadt } & \multicolumn{2}{|c|}{ vdmin } & \multicolumn{2}{|c|}{ Dspreadp } & \multicolumn{2}{|c|}{ vdmin } & \multicolumn{2}{|c|}{ dspreadn } \\
\hline Lag1.vdmin & 0.085 & $12.080^{* *}$ & 0.000 & 1.950 & 0.079 & $13.020^{* *}$ & 0.001 & 1.220 & 0.080 & $13.210^{* *}$ & 0.001 & $3.820^{* *}$ \\
\hline Lag2.vdmin & 0.084 & -1.810 & 0.000 & $-2.300^{* *}$ & 0.079 & $-2.090^{* *}$ & 0.001 & -1.150 & 0.079 & $-2.280^{* *}$ & 0.001 & $-3.970^{* *}$ \\
\hline Lag1.dspread_ & 16.484 & 1.140 & 0.083 & $-4.060^{* *}$ & 9.835 & 0.890 & 0.076 & $-9.400^{* *}$ & 10.953 & 0.080 & 0.076 & $-7.290^{* *}$ \\
\hline Lag2.dspread_ & 15.851 & -0.580 & 0.079 & $-2.450^{* *}$ & 9.780 & 0.670 & 0.075 & $-4.820^{* *}$ & 10.860 & -0.790 & 0.075 & $-2.930^{* *}$ \\
\hline Constant & 0.727 & $3.180^{* *}$ & 0.004 & 0.540 & 0.725 & $3.320^{* *}$ & 0.006 & -0.280 & 0.728 & $3.170^{* *}$ & 0.005 & 0.070 \\
\hline
\end{tabular}

Note. v1/5/n/dminare monthly minimum levels of the S\&P 100, 500, NASDAQ, and Dow Jones index option based VIX Index. dspread_ is the first order difference of the bid-ask spread per dollar equity price. The first two column groups are VAR with all returns involved; the second two column groups are VAR with only positive returns involved; and the last two column groups are with only negative returns. In each column group, the first column of data is the VAR regression coefficients and the second column of data is the t-statistics of the coefficients. $*$ is significant at $5 \%$ and $* *$ is significant at $1 \%$.

The relationships among the previous and current investor and broker sentiments using the modest investor sentiments, as exhibited in Table 8, are similar with Table 5 and Table 6 . This strengthens the robustness of the conclusion that the panic atmosphere presented in Table 6 dominates the market. Different return patterns continue to play lesser role in the VAR regressions. Previous investor sentiments positively affect the current investor and broker sentiments, while previous broker sentiments negatively affect current broker sentiments, and are not influential to the current investor sentiments.

The cross comparison from Table 5 to Table 8 reveals that the routine maps of investor and broker sentiment contagion are highly similar when the investor sentiment is at median, panic, or representative level. The routine map of such contagion is different when investor sentiment is at the optimistic level.Furthermore, the difference of the conclusions drawn from Table 4 and Table 5 to Table 8 is significant. Using the BWindex as the measure of investor sentiment, the interaction of broker and investor is less significant than using VIX as the indicator of investor fear. The plausible reason is that the components of the BW index are more diversified and thus less volatile than the option volatility-based VIX.

Table 8. VAR regression of VIX index monthly median and Bid-ask spread

\begin{tabular}{llllllllllllllll}
\hline v1median & \multicolumn{2}{c}{ v1median } & \multicolumn{2}{c}{ dspreadt } & \multicolumn{2}{c}{ v1median } & \multicolumn{2}{c}{ dspreadp } & \multicolumn{2}{c}{ v1median } & dspreadn \\
Lag1.v1median & 0.978 & $15.930^{* *}$ & 0.001 & $3.290^{* *}$ & 0.993 & $16.630^{* *}$ & 0.001 & $2.640^{* *}$ & 1.008 & $17.260^{* *}$ & 0.001 & $4.560^{* *}$ \\
Lag2.v1median & -0.106 & -1.770 & -0.001 & $-3.770^{* *}$ & -0.125 & $-2.130^{* *}$ & -0.001 & $-2.600^{* *}$ & -0.140 & $-2.410^{* *}$ & -0.001 & $-4.670^{* *}$ \\
Lag1.dspread_ & 51.291 & $3.250^{* *}$ & -0.339 & $-5.640^{* *}$ & 25.612 & $2.440^{* *}$ & -0.727 & $-12.780^{* *}$ & 9.196 & 0.840 & -0.467 & $-8.390^{* *}$ \\
Lag2.dspread_ & -22.389 & -1.420 & -0.189 & $-3.160^{* *}$ & -1.840 & -0.170 & -0.339 & $-5.890^{* *}$ & -8.301 & -0.760 & -0.238 & $-4.270^{* *}$ \\
Constant & 2.728 & $4.370^{* *}$ & 0.002 & 0.650 & 2.828 & $4.510^{* *}$ & -0.001 & -0.280 & 2.801 & $4.400^{* *}$ & 0.000 & -0.070 \\
\hline
\end{tabular}




\begin{tabular}{|c|c|c|c|c|c|c|c|c|c|c|c|c|}
\hline \multirow[b]{2}{*}{ Lag1.v5median } & \multicolumn{2}{|c|}{ v5median } & \multicolumn{2}{|c|}{ dspreadt } & \multicolumn{2}{|c|}{ v5median } & \multicolumn{2}{|c|}{ dspreadp } & \multicolumn{2}{|c|}{ v5median } & \multicolumn{2}{|c|}{ dspreadn } \\
\hline & 029 & $15.050^{* *}$ & 0.001 & $3.560^{* *}$ & 027 & $15.380^{* *}$ & 001 & $2.500^{* *}$ & 038 & $15.730^{* *}$ & 0.001 & $3.720^{* *}$ \\
\hline ian & 1 & & 001 & & 154 & & or & & 63 & & -0.001 & \\
\hline & 6 & 1.580 & -0.424 & $-6.440^{* *}$ & .447 & 0 & .756 & $-11.940^{* *}$ & .443 & 0.1 & -0.524 & -8.430 \\
\hline & -23.944 & -1.4 & -6 & $-3.720^{* *}$ & -0.643 & 0.000 & 17 & $-5.450^{* *}$ & -11.175 & -1.010 & -0.273 & $-4.390^{* *}$ \\
\hline \multirow[t]{2}{*}{ Constant } & 484 & $3.730^{*}$ & .001 & & 600 & *: & .004 & & & $3.760^{*}$ & -0.002 & -0.460 \\
\hline & \multicolumn{2}{|c|}{ vnmedian } & \multicolumn{2}{|c|}{ dspreadt } & \multicolumn{2}{|c|}{ vnmedian } & \multicolumn{2}{|c|}{ dspreadp } & \multicolumn{2}{|c|}{ vnmedian } & \multicolumn{2}{|c|}{ dspreadn } \\
\hline Lą & 0.964 & $8.570^{* *}$ & 0.001 & $4.220^{* *}$ & 0.926 & $8.630^{* *}$ & 0.001 & $2.610^{* *}$ & 0.960 & $8.980^{* *}$ & 0.001 & $3.470^{* *}$ \\
\hline Lag2.v & -0.095 & -0.890 & -0.001 & $-3.650^{* *}$ & -0.090 & -0.850 & -0.001 & -1.600 & -0.097 & -0.930 & -0.001 & $-2.660^{*}$ \\
\hline & 8.425 & 0.200 & & $-6.270^{* *}$ & 20.952 & & & $-8.820^{* *}$ & & & & $-8.190^{* *}$ \\
\hline & 845 & & -0.31 & & 885 & & 2 & & -51 & -1.900 & -0.354 & \\
\hline \multirow[t]{2}{*}{ Constant } & 056 & $2.010^{*}$ & .005 & -1.370 & $3.0 / 3$ & & .012 & & 0.220 & & -0.008 & -1.490 \\
\hline & \multicolumn{2}{|c|}{ vdmedian } & \multicolumn{2}{|c|}{ dspreadt } & \multicolumn{2}{|c|}{ vdmedian } & \multicolumn{2}{|c|}{ dspreadp } & \multicolumn{2}{|c|}{ vdmedian } & \multicolumn{2}{|c|}{ dspreadn } \\
\hline & 0.082 & $12.940^{* *}$ & 0.000 & $3.230^{* *}$ & 0.078 & $13.600^{* *}$ & 0.001 & $2.650^{* *}$ & 0.078 & $13.700^{* *}$ & 0.000 & $3.410^{* *}$ \\
\hline Lag2. & 0.080 & $-2.500^{* *}$ & 0.000 & $-3.560^{* *}$ & 0.077 & $-2.740^{* *}$ & 0.001 & & 0.077 & $-2.770^{* *}$ & 0.000 & $-3.480^{* *}$ \\
\hline Lag1.dspread & 20.591 & 1.460 & 0.079 & $-4.510^{* *}$ & 12.622 & 0.950 & 0.074 & $-9.840^{* *}$ & 14.001 & 0.520 & 0.076 & $-7.050^{* *}$ \\
\hline Lag2.dspread & 20.427 & -1.440 & 0.078 & $-2.870^{* *}$ & 12.695 & -0.450 & 0.075 & $-5.210^{* *}$ & 14.020 & -0.870 & 0.076 & $-2.900^{* *}$ \\
\hline Constant & 0.873 & $3.430^{* *}$ & 0.003 & 0.320 & .877 & $3.590^{* *}$ & 0.005 & -0.700 & 0.879 & $3.520^{* *}$ & 0.005 & -0.100 \\
\hline
\end{tabular}

Note. v1/5/n/dmedian are monthly median levels of the S\&P 100, 500, NASDAQ, and Dow Jones index option based VIX Index. dspread_is the first order difference of the bid-ask spread per dollar equity price. The first two column groups are VAR with all returns involved; the second two column groups are VAR with only positive returns involved; and the last two column groups are with only negative returns involved. In each column group, the first column of data is the VAR regression coefficients and the second column of data is the t-statistics of the coefficients. $*$ is significant at $5 \%$ and $* *$ is significant at $1 \%$.

The above descriptions of contagion focus on the linkages of sentiments instead of using previous sentiments as a tool in the market forecasting process. Therefore I adopt Granger causality tests to continue explore the causal dynamics of market sentiments in different return settings. Table 9 reports the Granger causality test results between investor sentiments and broker sentiments. I use two sources of investor sentiments: the BWsentiment index, and the Chicago Board Options Exchange VIX. Broker sentiment is still defined as the change of bid-ask spread divided by stock price. I further categorize stock returns into positive and negative groups and examine the change of bid-ask spreads of the stocks with the two return types in response to the shock of investor sentiment shock. The series with unit roots are first-order differentiated and all the variables in the Granger causality regressions are covariance stationary.

In Panel A of Table 9, broker sentiment is measured based on the bid-ask spread of stocks with all the returns in equity market. When BWindex is used as the proxy of investor sentiment, the broker and investor sentiments do not Granger cause each other. Nevertheless, when the VIX index is used as the proxy of investor sentiment, it can significantly granger cause broker sentiments, with only two exceptions: dvnmin (first order difference of the monthly minimum of NASDAQ-based VIX index) and vdmin (the monthly minimum of Dow-based VIX index). In contrast, broker sentiment can only Granger cause the median level of investor sentiment, while cannot affect the extreme panic or overoptimism among the investors. These results are consistent with the earlier VAR output: investor sentiment can greatly infect broker sentiments, while the opposite linkage is weak. In addition, investor sentiment is more (less) influential to the brokers when the market is pessimistic (optimistic), respectively.

When broker sentiment is measured based on the bid-ask spread of stocks that realize positive returns, the influence of sentiments are weaker, as presented in Panel B of Table 9. Only the median of the investor sentiments can persistently Granger cause broker sentiments, while broker sentiments have almost no role in affecting the investor enthusiasm. The reasoning of is plausible: broker is a group consists of brokerage companies, security dealers, and market maker, whose transaction decisions are based on fundamental researches rather than speculative herding behavior. This group is in general more rational than the investors in the market, who are the counterparties of brokers in equity transactions (Verma \& Verma, 2008). Therefore the brokers are less affected by the extreme investor fanaticism, though they are influenced by the consensus of investor sentiments. Investors, who are less rational compared to brokers, do not base their sentiments on the brokers' 
bid-ask spread signaling. These results contrast with the ones in the panic market environment presented below.

The most surprising and unanimous results are indicated in Panel $\mathrm{C}$ of Table 9. This panel involves only the bid-ask spreads of the stocks with negative returns. In panic atmosphere, investor sentiments can always Granger cause broker sentiments, but the opposite does not hold. In other words, when the realized returns of stocks are negative, brokers monitor investor panics closely and act correspondingly to avoid loss; while the panic of investors is not generated by brokers, but by the herding behaviors of themselves. The substantial stock price decline is not due to the widened bid-ask spread, but because of the pessimistic contagion among sellers; on the other side, observing such panic, the brokers widen their spreads thereafter.

Table 9. Investor sentiment and Bid-ask spread granger causality

\begin{tabular}{|c|c|c|c|c|c|c|c|c|c|}
\hline \multirow{4}{*}{$\begin{array}{l}\text { Market } \\
\text { Sentiment }\end{array}$} & \multicolumn{3}{|c|}{ Panel A } & \multicolumn{3}{|c|}{ Panel B } & \multicolumn{3}{|c|}{ Panel C } \\
\hline & Broker & Broker & Market & Broker & Broker & Market & Broker & Broker & Market \\
\hline & Sentiment & Shock & Shock & Sentiment & Shock & Shock & Sentiment & Shock & Shock \\
\hline & & $\chi^{2}$ & $\chi^{2}$ & & $\chi^{2}$ & $\chi^{2}$ & & $\chi^{2}$ & $\chi^{2}$ \\
\hline dbw & dspreadt & 2.298 & 2.989 & dspreadp & $7.131^{*}$ & 2.558 & dspreadn & 1.396 & 0.177 \\
\hline vix100avg & dspreadt & 3.384 & $14.424 * *$ & dspreadp & 0.834 & $12.164 * *$ & dspreadn & 1.226 & $21.355 * *$ \\
\hline vix100max & dspreadt & 1.849 & $6.647^{*}$ & dspreadp & 0.291 & $9.522 * *$ & dspreadn & 0.611 & $9.236 * *$ \\
\hline vix100median & dspreadt & $17.215^{* *}$ & $14.274 * *$ & dspreadp & $9.529 * *$ & $7.265^{*}$ & dspreadn & 2.044 & $22.610^{* *}$ \\
\hline vix100min & dspreadt & $18.835 * *$ & $12.350 * *$ & dspreadp & $13.877 * *$ & 3.509 & dspreadn & 2.982 & $25.370^{* *}$ \\
\hline vix500avg & dspreadt & 5.407 & $12.014 * *$ & dspreadp & 1.348 & 5.405 & dspreadn & 2.540 & $13.711^{* *}$ \\
\hline vix 500max & dspreadt & 3.852 & $8.134 *$ & dspreadp & 0.759 & $6.084^{*}$ & dspreadn & 2.764 & $6.268^{*}$ \\
\hline vix500median & dspreadt & $6.942^{*}$ & $13.972 * *$ & dspreadp & 3.178 & $6.243^{*}$ & dspreadn & 1.364 & $14.431 * *$ \\
\hline vix $500 \mathrm{~min}$ & dspreadt & 4.747 & $9.606^{* *}$ & dspreadp & 2.315 & 1.372 & dspreadn & 1.421 & $22.647 * *$ \\
\hline vixnasavg & dspreadt & $6.175^{*}$ & $12.867 * *$ & dspreadp & 0.571 & 5.437 & dspreadn & 3.638 & $12.350 * *$ \\
\hline vixnasmax & dspreadt & 2.847 & $10.256^{* *}$ & dspreadp & 0.390 & 5.444 & dspreadn & 1.312 & $7.434^{*}$ \\
\hline vixnasmedian & dspreadt & $6.147^{*}$ & $17.775^{* *}$ & dspreadp & 1.333 & $8.177^{*}$ & dspreadn & 4.091 & $12.304 * *$ \\
\hline dvixnasmin & dspreadt & 5.952 & 4.197 & dspreadp & 0.032 & 1.390 & dspreadn & 4.811 & $17.671 * *$ \\
\hline vixdowavg & dspreadt & 4.468 & $12.835^{* *}$ & dspreadp & 1.337 & $7.677^{*}$ & dspreadn & 1.242 & $12.993 * *$ \\
\hline vixdowmax & dspreadt & 4.005 & $13.213 * *$ & dspreadp & 1.676 & $11.029 * *$ & dspreadn & 0.644 & $7.569^{*}$ \\
\hline vixdowmedian & dspreadt & $6.057^{*}$ & $12.680 * *$ & dspreadp & 2.198 & $7.007^{*}$ & dspreadn & 1.716 & $12.666^{* *}$ \\
\hline vixdowmin & dspreadt & 2.253 & 5.386 & dspreadp & 0.850 & 1.509 & dspreadn & 0.833 & $16.121^{* *}$ \\
\hline
\end{tabular}

Note. Panel A is the market sentiment and bid-ask spread with all return periods; Panel B is the market sentiment and bid-ask spread with positive return periods; Panel $\mathrm{C}$ is the market sentiment and bid-ask spread with negative return periods. BW and VIX serve as market sentiment proxies. The bid-ask spread per dollar equity price is employed as broker sentiment measure. Significant influence of broker-initiated shocks indicate that broker sentiment Granger causes investor sentiment; while significant influence of market-initiated shocks indicate that investor sentiment Granger causes the broker sentiment. All series initialed with d are the ones with unit roots and are adjusted to be covariance stationary. ${ }^{*}$ is significant at $5 \%$ and ${ }^{* *}$ is significant at $1 \%$.

\section{Concluding Remarks}

This paper first establishes the measures of investor sentiments and broker sentiments with data from Chicago Board Option Exchange, CRSP, and BW Index. Investor sentiments are categorized into extreme, modest, and representative levels. Then I use unrestricted VAR and Granger causality tests to reveal the sentiments spillover between the counterparties of equity transaction. All the tests are separately performed at positive and negative return environments.

Using BWindex as the investor sentiment, I find that historical broker (market) sentiments have no impact on the current market (broker) sentiments. The brokers frequently reverse their previous sentiments to the opposite side, while the current market sentiment neither memorizes nor reverses the previous market sentiment.

Using VIX as the investor sentiment indicator, this paper concludes that: first, previous investor sentiments with one lag will affect the current investor sentiments and broker sentiments in the same direction for all the positive and negative return types. Second, previous broker sentiments with one lag affect the current broker sentiment to the same direction, yet not affecting the current market sentiment. Third, the earlier investor sentiments with two lags affect the current broker sentiment in the opposite way, compared to the later investor sentiments with one lag. Such phenomenon is significantly consistent in S\&P 100, 500, and NASDAQ, yet different in terms of the 
Dow-based VIX. The threeformer indices contain more sentiment corrections, while the DOW-based market sentiment is more persistent over time.

The VAR regression with the monthly maximum value of the daily VIX series, which represents extreme market fear, concludes that previous investor panics with one lag will continue affect the current investorpanics and broker panics. In contrast, broker panicsin the previous one and two months will reduce the current broker panics and will not cause current investor panics. Extremely negative investor sentiment can dominate in the equity market, yet the extremely positive sentiment is less influential. The extreme atmosphere in the equity market in the United States is asymmetric. For stocks with positive returns, investor sentiments do not affect broker sentiments, and vice versa.

When BWindex is used as the proxy of investor sentiment, the broker and investor sentiments do not Granger cause each other. Nevertheless, when the VIX index is used as the proxy of investor sentiment, only the median of the investor sentiments can persistently Granger cause broker sentiments, while broker sentiments have almost no role in affecting the investor enthusiasm. In panic atmosphere, investor sentiments can always Granger cause broker sentiments, but the opposite does not hold. The steep stock price decline is not because of the widened bid-ask spread, but because of the pessimistic contagion among sellers; widened spread is in fact the result of the sharp price drop.

As the conclusions of this paper are somewhat different with the two investor sentiment indices, identifying measures for investor and broker sentiments seems worthy offurther research. In addition, the relationship between bond broker and investor sentiments in the parallel fixed-income market is also an interesting direction to move on. I leave those extensions for the future.

\section{References}

Akhtar, S., Faff, R., Oliver, B., \& Subrahmanyam, A. (2012). Stock salience and the asymmetric market effect of consumer sentiment news. Journal of Banking \& Finance, 36, 3289-3301. http://dx.doi.org/10.1016/j.jbankfin.2012.07.019

Alimov, A., \& Mikkelson, W. (2012). Does favorable investor sentiment lead to costly decisions to go public? Journal of Corporate Finance, 18, 519-540. http://dx.doi.org/10.1016/j.jcorpfin.2012.02.004

Atkins, A. B., \& Dyl, E. A. (1997). Transactions costs and holding periods for common stocks. Journal of Finance, 1, 309-325. http://dx.doi.org/10.2307/2329565

Baker, M., \& Stein, J. C. (2004). Market liquidity as a sentiment indicator. Journal of Financial Markets, 7, 271299. http://dx.doi.org/10.1016/j.finmar.2003.11.005

Baker, M., \& Wurgler, J. (2006). Investor sentiment and the cross-section of stock returns. Journal of Finance, 61, 1125-1165. http://dx.doi.org/10.1111/j.1540-6261.2006.00885.x

Baker, M., \& Wurgler, J. (2007). Investor sentiment in the stock market. The Journal of Economic Perspectives, 21, 129-151. http://dx.doi.org/10.3386/w13189

Baker, M., Wurgler, J., \& Yuan, Y. (2012). Global, local, and contagious investor sentiment. Journal of Financial Economics, 104, 272-287. http://dx.doi.org/10.1016/j.jfineco.2011.11.002

Ben-Rephael, A., Kandel, S., \& Wohl, A. (2012). Measuring investor sentiment with mutual fund flows. Journal of Financial Economics, 104, 363-382. http://dx.doi.org/10.1016/j.jfineco.2010.08.018

Berger, D., \& Turtle, H. J. (2012). Cross-sectional performance and investor sentiment in a multiple risk factor model. Journal of Banking \& Finance, 36, 1107-1121. http://dx.doi.org/10.1016/j.jbankfin.2011.11.001

Brown, G. W., \& Cliff, M. T. (2004). Investor sentiment and the near-term stock market. Journal of Empirical Finance, 11, 1-27. http://dx.doi.org/10.1016/j.jempfin.2002.12.001

Chen, M., Chen, P., \& Lee, C. (2013). Asymmetric effects of investor sentiment on industry stock returns: Panel data evidence. Emerging Market Review, 14, 35-54. http://dx.doi.org/10.1016/j.ememar.2012.11.001

Corredor, P., Ferrer, E., \& Santamaria, R. (2013). Investor sentiment effect in stock markets: Stock characteristics or country-specific factors? International Review of Economics and Finance, 27, 572-591. http://dx.doi.org/10.1016/j.iref.2013.02.001

Glosten, L., \& Harris, L. (1988). Estimating the components of the bid/ask spread. Journal of Financial Economics, 21, 123-142. http://dx.doi.org/10.1016/0304-405x(88)90034-7

Gospodinov, N., Herrera, A. M., \& Pesavento, E. (2013). Unit roots, cointegration and pre-testing in VAR 
models. Retrieved July 13, 2013, from http://www.indiana.edu/ econdept/workshops/

Joseph, K., Wintoki, M. B., \& Zhang, Z. (2011). Forecasting abnormal stock returns and trading volume using investor sentiment: Evidence from online search. International Journal of Forecasting, 27, 1116-1127. http://dx.doi.org/10.1016/j.ijforecast.2010.11.001

Kumar, A., \& Lee, C. M. C. (2006). Retail investor sentiment and return comovements. Journal of Finance, 61, 2451-2486. http://dx.doi.org/10.1111/j.1540-6261.2006.01063.x

Laborda, R., \& Olmo, J. (2013). Investor sentiment and bond risk premia. Journal of Financial Markets. http://dx.doi.org/10.1016/j.finmar.2013.05.008

Menyah, K., \& Paudyal, K. (2000). The components of bid-ask spreads on the London Stock Exchange. Journal of Banking and Finance, 24, 1767-1785. http://dx.doi.org/10.1016/s0378-4266(99)00102-8

Palomino, F., Renneboog, L., \& Zhang, C. (2009). Information salience, investor sentiment, and stock returns: The case of British soccer betting. Journal of Corporate Finance, 25, 368-387. http://dx.doi.org/10.1016/j.jcorpfin.2008.12.001

Stambaugh, R. F., Yu, J., \& Yuan, Y. (2012). The short of it: Investor sentiment and anomalies. Journal of Financial Economics, 104, 288-302. http://dx.doi.org/10.1016/j.jfineco.2011.12.001

Verma, R., \& Verma, P. (2008). Are survey forecasts of individual and institutional investor sentiments rational? International Review of Financial Analysis, 17, 1139-1155. http://dx.doi.org/10.1016/j.irfa.2007.04.001

\section{Copyrights}

Copyright for this article is retained by the author(s), with first publication rights granted to the journal.

This is an open-access article distributed under the terms and conditions of the Creative Commons Attribution license (http://creativecommons.org/licenses/by/3.0/). 